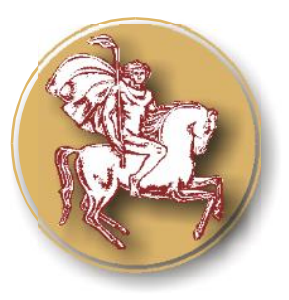

Original Contribution

\title{
WAS THE CLASSIFICATION ABLE TO DIVIDE DOGS WITH MYXOMATOUS MITRAL VALVE DISEASE ACCORDING TO THE SEVERITY OF THE DISEASE?
}

\author{
A. Pankov* \\ Department of Internal Non-Infectious Diseases, Pathology and Pharmacology, Faculty of Veterinary \\ Medicine, University of Forestry, Sofia, Bulgaria
}

\begin{abstract}
Using the simultaneous readings of the left ventricular remodeling model and the left ventricular weight to body weight ratio, the Gaasch and Zile classification was able to distinguish almost completely $(95 \%)$ the dogs without pulmonary edema from those with pulmonary edema in cases of MMVD (myxomatous mitral valve disease) with an established limit for the left ventricular mass of $7.478 \mathrm{~g} / \mathrm{kg}$ between the two groups. In one of the twenty animals surveyed, the classification failed. We assume that this is related to the exacerbation of the disease and the change of its chronic course due to an additional cause.
\end{abstract}

Key words: degeneration, echocardiography, left ventricular, pulmonary edema, X-ray system.

\section{INTRODUCTION}

Myxomatous mitral valve disease (MMVD) is characterized by myxomatous degeneration of the valvular leaflets. Its progression leads to the thickening and deformation of the leaflets, which disrupts their coaptation. The systolic regurgitation of blood in the left atrium is the main cause of increased volume overload of the left half of the heart and the development of left-sided heart failure in this disease. Although is it proven that LVH (left ventricular hypertrophy) is an independent risk factor for unwanted cardiovascular events, regardless of their etiology (1-3) in the accessible literature, we have not identified serious attempts to classify patients with MMVD. We assume that this is related to the suboptimal categorization of eccentric geometry, which is an important limitation of the previous remodeling models (4). To overcome these constraints, Gaasch and Zile classification of heart remodeling (5) has been used and has been found to be very appropriate for classifying patients with severe aortic

\footnotetext{
*Correspondence to: Pankov A. G., University of Forestry, Faculty of Veterinary Medicine, No10 Kliment Ohridski blvd, 1797 Sofia, Bulgaria, E-mail: pannkov@abv.bg
}

stenosis (6). According to the authors, this classification can be used to assess cardiovascular risk, which improves individual therapeutic management. This gives us a reason to examine how the new classification will manage as far as the most common heart disease in the dog-MMVD, is concerned.

The purpose of this study is to attempt to use the Gaasch and Zile classification to determine the progression of MMVD in dogs.

\section{MATERIALS AND METHODS}

Twenty dogs with MMVD based on X-ray examination were divided according to the absence or presence of pulmonary edema. Chest radiographs were performed with direct digital X-ray (Sedecal - DR X-ray system) in the LLR (left lateral) and VD (ventrodorsal) projections. Of all the dogs that participated in the study, two groups were formed:

- the group without edema included 9 (6 male and 3 female) dogs aged between 7 and 18 years, weighing between 3.1 and $12.5 \mathrm{~kg}$. Breed composition - Shi Tzu - 1, Bishon Frize - 1, Pincher - 1, Maltese - 1, Dachshund - 2, Poodle - 1, Yorkshire terrier - 1 and mix breed -1 . 
- the group with edema was formed by 11 dogs ( 8 male and 3 female) aged between 8 and 15 years, weighing between 4.5 to $10 \mathrm{~kg}$. Breed composition - Dachshund - 1, Shi Tzu 1, Cavalier King Charles - 1, Pekingese - 2 and Mix breed -6 .

The echocardiographic examination was performed with a My Lab 70 vet XV apparatus (Doppler apparatus manufactured by the Italian company Esaote). The animals were examined with specialized cardiological phasometric transducers PA023E (frequency $4-11 \mathrm{MHz}$ ) and PA122E (frequency 3-7 MHz), suitable for cardiac patients from the small dog breeds, in the right parasternal position.

The Gaasch and Zile's classification was modified in order to make the single use of Mmode echocardiography possible. For this purpose, when assessing the left ventricular enlargement, we replaced the left-ventricular volume with the weight-based aortic root dimension normalized end diastolic left ventricular inner diameter (LVID/Aow). As normal limits for LVID/Aow in dogs we used the limits 1.305-1.861 (7). Thus, we avoided the overestimation of the small differences in primary echocardiographic dimensions in the geometric method for calculating volumes calculated on the basis of M-mode echocardiography $(8,9)$.

The LV mass was determined using the formula: $\mathrm{LVM}=0.8 \times 1.04 \times\left[(\mathrm{IVS}+\mathrm{LVID}+\mathrm{PWT})^{3}-\right.$ $\left.\mathrm{LVID}^{3}\right]+0.6$ g. $(1,10)$. We then indexed the left ventricular mass in grams to body weight in kilograms $(\mathrm{g} / \mathrm{kg})$. After we have complied with the results of authors who have studied the left ventricular hypertrophy and after comparing our results with the volume overload model defined by the classification, we assumed the range 4.7 $5.1(\mathrm{~g} / \mathrm{kg})$ as normal values (2). The relative wall thickness (RWT) was calculated to estimate the degree of concentric hypertrophy: RWT = LVPWT/((LVPWT + LVID)/2). For normal parameters, we used the values between $(0.38$ 0.48) after we have complied with the values established by authors who have previously worked with RWT (10). The classification model imposed a slight increase in the range in order to make the classification of the patients in the study possible.

\section{RESULTS}

While studying the individual parameters determining the classification of dogs without pulmonary edema (Table 1), we established the following guidelines: LVID/Aow from 1.455 to 2.336; LVM from $4.719 \mathrm{~g} / \mathrm{kg}$ to $10.706 \mathrm{~g} / \mathrm{kg}$; RWT from 0.332 to 0.54 . According to our results in this group, the physiological hypertrophy found in 4 (44.5\%) of dogs was the most common model of heart remodeling in which these indicators moved within the corresponding range: LVID/Aow from 2.025 to 2.336; LVM from $9.521 \mathrm{~g} / \mathrm{kg}$ to $10.706 \mathrm{~g} / \mathrm{kg}$; RWT from 0.384 to 0.457 . In 4 of the dogs (44.4\%) without pulmonary edema, we found remodeling other than physiological hypertrophy, of which 2 dogs (22.2\%) had eccentric hypertrophy with values of the classification parameters as follows: LVID/Aow - 2.251 and 2.293; LVM - $7.478 \mathrm{~g} / \mathrm{kg}$ and $8.74 \mathrm{~g} / \mathrm{kg}$; RWT 0.332 and 0.337 . For 1 dog $(11.1 \%)$ according to the values: LVID/Aow - 1.779; LVM - $8.57 \mathrm{~g} /$ $\mathrm{kg}$; RWT -0.54 , we have identified Concentric Hypertrophy. For $1 \operatorname{dog}(11.1 \%)$ we found Concentric Remodeling with values of the classification parameters: LVID/Aow - 1.455; LVM - $4.719 \mathrm{~g} / \mathrm{kg}$; RWT - 0.496. For $1 \mathrm{dog}$ $(11.1 \%)$ we found a lack of ventricular remodeling - Normal Ventricle, with values of the parameters determining the classification: LVID/Aow - 1.751; LVM - $5.072 \mathrm{~g} / \mathrm{kg}$; RWT 0.397 .

Table 1. Left ventricular remodeling, individual values of the dogs with MMVD without pulmonary edema

\begin{tabular}{|c|c|c|c|c|c|}
\hline \multirow{2}{*}{$\begin{array}{l}\text { Dog № } \\
\text { (sex) }\end{array}$} & \multicolumn{5}{|c|}{ Indicator } \\
\hline & Weight & LVID/Aow & LVM (g/kg) & RWT & Classification \\
\hline $1(\mathbf{F})$ & $8,7 \mathrm{~kg}$ & $2.025(\mathbf{H})$ & $9.521 \mathrm{~g} / \mathrm{kg}(\mathbf{H})$ & $0.457(\mathbf{N})$ & Physiologic Hypertrophy \\
\hline $2(\mathrm{M})$ & $12,5 \mathrm{~kg}$ & $1.751(\mathbf{N})$ & $5.072 \mathrm{~g} / \mathrm{kg}(\mathbf{N})$ & $0.397(\mathbf{N})$ & Normal Ventricle \\
\hline 3 (M) & $7,7 \mathrm{~kg}$ & $2.293(\mathbf{H})$ & $8.74 \mathrm{~g} / \mathrm{kg} \quad$ (H) & $0.337(\mathbf{L})$ & Eccentric Hypertrophy \\
\hline $4(\mathrm{M})$ & $4,3 \mathrm{~kg}$ & $1.779(\mathbf{N})$ & $8.57 \mathrm{~g} / \mathrm{kg} \quad$ (H) & $0.54(\mathbf{H})$ & Concentric Hypertrophy \\
\hline $5(F)$ & $5,8 \mathrm{~kg}$ & $2.164(\mathbf{H})$ & $10.479 \mathrm{~g} / \mathrm{kg}(\mathbf{H})$ & $0.399(\mathbf{N})$ & Physiologic Hypertrophy \\
\hline $6(\mathrm{M})$ & $11,0 \mathrm{~kg}$ & $2.336(\mathbf{H})$ & $10.261 \mathrm{~g} / \mathrm{kg}(\mathbf{H})$ & $0.384(\mathbf{N})$ & Physiologic Hypertrophy \\
\hline $7(\mathrm{M})$ & $5,4 \mathrm{~kg}$ & $1.455(\mathbf{N})$ & $4.719 \mathrm{~g} / \mathrm{kg}(\mathbf{N})$ & $0.496(\mathbf{H})$ & Concentric Remodeling \\
\hline $8(\mathrm{M})$ & $3,1 \mathrm{~kg}$ & $2.036(\mathbf{H})$ & $10.706 \mathrm{~g} / \mathrm{kg}(\mathbf{H})$ & $0.432(\mathbf{N})$ & Physiologic Hypertrophy \\
\hline $9(\mathbf{F})$ & $4,3 \mathrm{~kg}$ & $2.251(\mathbf{H})$ & $7.478 \mathrm{~g} / \mathrm{kg}(\mathbf{H})$ & $0.332(\mathbf{L})$ & Eccentric Hypertrophy \\
\hline
\end{tabular}

$\mathrm{M}$ - male; F - female; L - low; $\mathrm{N}$ - normal(3.8-4.7); H - high

LVID/Aow - weight-based aortic root dimension normalized end diastolic left ventricular inner diameter; LVM left ventricular mass; RWT - relative wall thickness; Gaasch and Zile classification, 2011. 
While studying the individual parameters determining the classification of dogs with pulmonary edema (Table 2), we established the following guidelines: LVID/Aow from 1.506 to 3.005 ; LVM from $8.874 \mathrm{~g} / \mathrm{kg}$ to $13.333 \mathrm{~g} / \mathrm{kg}$; RWT from 0.252 to 0.629 . According to our results in this group, the Excentric Hypertrophy found in 9 of the dogs $(81.8 \%)$ is the most common model of cardiac remodeling in which these indicators varied within the respective limits: LVID/Aow from 2.422 to 3.005 ; LVM from $9,149 \mathrm{~g} / \mathrm{kg}$ to
$13.333 \mathrm{~g} / \mathrm{kg}$; RWT from 0.252 to 0.377 . In 2 of the dogs $(18.2 \%)$ with pulmonary edema, we found remodeling other than eccentric hypertrophy, of which $1 \operatorname{dog}(9.1 \%)$ had a Physiologic Hypertrophy with values of the classification parameters as follows: LVID/Aow - 1.965; LVM - 8.874 g/kg; RWT 0.47 . For 1 dog $(9.1 \%)$ in accordance with the values: LVID/Aow - 1.506; LVM - 10,609 $\mathrm{g} / \mathrm{kg} ; \mathrm{RWT}$ - 0.629, we have identified Concentric Hypertrophy.

Table 2. Left ventricular remodeling, individual values of the dogs with MMVD with pulmonary edema

\begin{tabular}{|c|c|c|c|c|c|}
\hline \multirow{2}{*}{$\begin{array}{ll}\text { Dog } & \text { № } \\
(\text { sex }) & \end{array}$} & \multicolumn{5}{|c|}{ Indicator } \\
\hline & Weight & LVID/Aow & LVMass (g/kg) & RWT & Classification \\
\hline $1(\mathbf{M})$ & $5,1 \mathrm{~kg}$ & $2.58(\mathbf{H})$ & $13.333 \mathrm{~g} / \mathrm{kg}(\mathbf{H})$ & $0.331(\mathbf{L})$ & Eccentric Hypertrophy \\
\hline $2(M)$ & $6,6 \mathrm{~kg}$ & $1.965(\mathbf{H})$ & $8.874 \mathrm{~g} / \mathrm{kg}(\mathbf{H})$ & $0.47(\mathbf{N})$ & Physiologic Hypertrophy \\
\hline $3(\mathbf{M})$ & $7,0 \mathrm{~kg}$ & $1.506(\mathbf{N})$ & $10.609 \mathrm{~g} / \mathrm{kg}(\mathbf{H})$ & $0.629(\mathrm{H})$ & Concentric Hypertrophy \\
\hline $4(\mathrm{M})$ & $10,0 \mathrm{~kg}$ & $2.452(\mathbf{H})$ & $9,149 \mathrm{~g} / \mathrm{kg}(\mathbf{H})$ & $0.293(\mathbf{L})$ & Eccentric Hypertrophy \\
\hline $5(\mathrm{~F})$ & $4,8 \mathrm{~kg}$ & $3.005(\mathbf{H})$ & $13.01 \mathrm{~g} / \mathrm{kg}(\mathbf{H})$ & $0.278(\mathbf{L})$ & Eccentric Hypertrophy \\
\hline $6(F)$ & $3,6 \mathrm{~kg}$ & $2.709(\mathbf{H})$ & $12.364 \mathrm{~g} / \mathrm{kg}(\mathbf{H})$ & $0.312(\mathbf{L})$ & Eccentric Hypertrophy \\
\hline $7(\mathrm{M})$ & $4,5 \mathrm{~kg}$ & $2.605(\mathbf{H})$ & $11.933 \mathrm{~g} / \mathrm{kg}(\mathbf{H})$ & $0.352(\mathbf{L})$ & Eccentric Hypertrophy \\
\hline $8(\mathbf{M})$ & $9,8 \mathrm{~kg}$ & $2.85(\mathbf{H})$ & $12.946 \mathrm{~g} / \mathrm{kg}(\mathbf{H})$ & $0.322(\mathbf{L})$ & Eccentric Hypertrophy \\
\hline $9(\mathrm{M})$ & $4,7 \mathrm{~kg}$ & $3.005(\mathbf{H})$ & $13.289 \mathrm{~g} / \mathrm{kg}(\mathbf{H})$ & $0.252(\mathrm{~L})$ & Eccentric Hypertrophy \\
\hline $10(\mathrm{~F})$ & $4,9 \mathrm{~kg}$ & $2.615(\mathbf{H})$ & $12.999 \mathrm{~g} / \mathrm{kg}(\mathbf{H})$ & $0.343(\mathbf{L})$ & Eccentric Hypertrophy \\
\hline $11(\mathrm{M})$ & $4,9 \mathrm{~kg}$ & $2.422(\mathbf{H})$ & $9.761 \mathrm{~g} / \mathrm{kg}(\mathbf{H})$ & $0.377(\mathbf{L})$ & Eccentric Hypertrophy \\
\hline
\end{tabular}

$\mathrm{M}$ - male; $\mathrm{F}$ - female; $\mathrm{L}$ - low; $\mathrm{N}$ - normal; $\mathrm{H}$ - high

LVID/Aow - weight-based aortic root dimension normalized end diastolic left ventricular inner diameter; LVM left ventricular mass; RWT - relative wall thickness; Gaasch and Zile classification, 2011.

\section{DISCUSSION}

Gaasch and Zile describe the rates of remodeling associated with the progression of mitral regurgitation. According to them, the response of the left ventricular walls to the volume overload consists of a progressive expansion of the ventricle with characteristic changes in the mass of LV and RWT (5). These changes depend partly on the gravity and duration of the overload (3). In the case of acute MR, the earliest change is an increase in $\mathrm{LV}$ volume, which is disproportionate to the LV mass. Eccentric remodeling was not found in the animals we examined. The reason for this is that we chose animals with a more advanced phase of the disease in which cough is clinically observed. This early transient stage is followed by the development of "volume overload hypertrophy", the RWT returns to normal and maintains a normal systolic function. In the case of compensated MR, remodeling of the LV resembles the adaptive changes seen in physiological hypertrophy. The thus described progress of the influence of volume overload on the left ventricular remodeling coincides completely with the results obtained in dogs with MMVD without manifestation of signs of left-sided heart failure. In the dog with eccentric hypertrophy without pulmonary edema (No.9), we found the lowest ratio of left ventricular mass to weight $(7.478 \mathrm{~g} / \mathrm{kg})$ compared to the dogs with eccentric hypertrophy but with established pulmonary edema. Concentric hypertrophy was observed in dog No. 4 in the non-pulmonary edema group and in dog No. 3 in the pulmonary edema group. On a detailed examination of the left ventricular remodeling model, in these two patients, we found a significantly higher deviation of the dog with pulmonary edema from the normal range we have set compared to the dog without pulmonary edema. We assume that in these two dogs the remodeling is due to an underlying illness, in which the ventricular afterload was initially increased and then, subsequently, the ventricular preload. In the dog with Physiologic Hypertrophy patient No. 2 in the group of dogs with pulmonary edema, the classification failed. The dimensions determining its ventricle remodeling were very similar to those found in dogs without 
pulmonary edema. This dog is not excluded from the study as it follows the actual clinical course of MMVD and the possibility of complications arising from the progression of mitral degeneration, for example elevated blood pressure or the occurrence of an incident like a ruptured chord in patients with a background of a previously established relatively benign MMVD (11). The previous authors report a comparatively mild clinical picture that has been favorably influenced by cardiac therapy. According to them, this is due to the lack of high-grade left ventricle remodeling. Rupturing the chord does not always lead to rapid progression of the disease. Acutely ruptured chordae tendineae could produce the sudden onset of strikingly loud, high-pitched murmur, regardless of clinical sign severity. (12). In this dog, we found a strong systolic peak murmur during auscultation and in the echocardiographic study, we found signs of ruptured chords. The described acute exacerbation of the signs of left-sided heart failure in connection to a ruptured chord (13) appears to be a possible cause of a lack of adequate to the pulmonary edema left ventricular remodeling in patient No. 2. This gives us reason to assume that the classification correctly indicates in which patients with MVD the progression of the disease is associated with a purely chronic volume load and in which patients with MVD disease progression is associated with a sharp exacerbation of the signs due to another reason. Further studies conducted with more dogs are needed to test this hypothesis of ours. The late MR stage is characterized by reduced RWT and impaired systolic function. Thus, in chronic MR, the LV mass can be increased two or three times while the RWT ranges from normal to low. Left ventricular remodeling can be classified as a model of physiological hypertrophy, but in most cases, eccentric hypertrophy with RWT is found below the normal lower limit $(14,15)$. These assertions by the previous authors received a complete confirmation by the results obtained with the 9 dogs with pulmonary edema, classified according to our limits for left ventricular remodeling. We suppose these are the dogs in which the remodeling develops as a pure chronic volume overload model.

In the examined patients and their classification compared to the limits set by us, the Gaasch and Zile classification was very suitable for detecting the disease progression in dogs with MMVD. Despite the overlapping of one of the models of remodeling in the examined animals without pulmonary edema and with pulmonary edema, we found convincing differences that may be a prerequisite for more detailed studies with more patients.

\section{REFERENCES}

1. Devereux RB, Alonso DR, Lutas EM, et al.. Echocardiographic assessment of left ventricular hypertrophy: Comparison to necropsy findings. Am J Cardiol; 57:450458, 1986

2. Kevin C. Dellsperger, Jennifer L. Clothier, Jane A. Hartnett, Linda M. Haun, and Melvin L. Marcus. Acceleration of the Wavefront of Myocardial Necrosis By Chronic Hypertension and Left Ventricular Hypertrophy in Dogs. Circulation Research. Vol 63, No 1, 87-96, 1988

3. Gaasch WH, Meyer TE. The left ventricular response to mitral regurgitation: implications for therapy. Circulation.118:2298-2303, 2008

4. Marwick TH, Gillebert TC, Aurigemma G, Chirinos J, Derumeaux G, Galderisi M. Recommendations on the use of echocardiography in adult hypertension: a report from the European Association of Cardiovascular Imaging (EACVI) and the American Society of Echocardiography (ASE). Eur Heart $J$ Cardiovasc Imaging. 16:577-605, 2015

5. Gaasch, W. H., M. R. Zile. Left Ventricular Structural Remodeling in Health and Disease With Special Emphasis on Volume, Mass, and Geometry. Journal of the American College of Cardiology, 58, 17, 1733-1740, 2011

6. Di Nora C, Cervesato E, Cosei I, et al. New classification of geometric ventricular patterns in severe aortic stenosis: Could it be clinically useful? Echocardiography. 00:1-8, 2018

7. Brown, D. J., J. E. Rush, J. MacGregor, J. N. Ross Jr, B. Brewer, W. M. Rand Mmode echocardiographic ratio indices in normal dogs, cats, and horses: A novel quantitative method. Journal of Veterinary Internal Medicine, 17, 653-662, 2003

8. Serres, F., V. Chetboul, R. Tissier, L. Poujol, V. Gouni, C. C. Sampedrano, J. L. Pouchelon Comparison of 3 ultrasound methods for quantifying left ventricular systolic function: correlation with disease severity and prognostic value in dogs with mitral valve disease. Journal of Veterinary Internal Medicine, 22, 566-577, 2008 
9. Tidholm, A., A.B. Westling, K. Höglund, I. Ljungvall, J. Häggström. Comparisons of 3,2-dimensional, and M-Mode echocardiographical methods for estimation of left chamber volumes in dogs with and without acquired heart disease. Journal of Veterinary Internal Medicine, 24, 6, 14141420, 2010

10.Marie Claude Be'langer, Rocky Di Fruscia, Jean G. Dumesnil, and Philippe Pibarot Usefulness of the indexed effective orifice area in the assessment of subaortic stenosis in the dog. J Vet Intern Med;15:430-437, 2001

11.Sa-Hee Min, Min-Hee Kang, Hee-Myung Park. Musical murmur in a dog with acute chordae tendineae rupture. Korean $\mathrm{J}$ Vet Res 53(4) : 263-264, 2013

12.Franc,ois Serres, Vale'rie Chetboul, Renaud Tissier, Carolina Carlos
Sampedrano, Vassiliki Gouni, Audrey P. Nicolle, and Jean-Louis Pouchelon. Chordae tendineae Rupture in Dogs with Degenerative Mitral Valve Disease: Prevalence, Survival, and Prognostic Factors (114 Cases, 2001-2006). J Vet Intern Med; 21:258-264, 2007.

13.Kittleson MD. Myxomatous atrioventricular valvular degeneration.In: Kittleson MD, Kienle RD (eds.). Small Animal Cardiovascular Medicine. pp. 297318, Mosby, St. Louis, 1998.

14.Grossman W, Jones D, McLaurin L. Wall stress and patterns of hypertrophy in the human left ventricle. J Clin Invest;56:5664, 1975

15.Dumesnil JG, Shoucri RM. Effect of the geometry of the left ventricle on the calculation of the ejection fraction. Circulation; 65: 91-98, 1982. 